\title{
Utilization of organic waste and soil microorganisms in compost making and its application in hybrid corn cultivation in the middle school environment in Medan City
}

\author{
Diana Sofia Hanafiah ${ }^{1 *}$, Muhdi $^{2}$ \\ ${ }^{1}$ Program Studi Agroteknologi, Fakulty of Agriculture Universitas Sumatera Utara \\ ${ }^{2}$ Departemen Manajemen Hutan, Fakulty of Forestry Universitas Sumatera Utara \\ *Email: diana.hanafiah@usu.ac.id
}

\begin{abstract}
The existence of educational institutions is very important and strategic to educate a quality generation. The target of this service program is junior high school in Medan, namely MTs P.P. Raudhatul Hasanah at the Ar-Raudlatul Hasanah Islamic Boarding School in Medan. Waste management and utilization and through the provision of soil microorganisms into compost and its role in land use through hybrid maize cultivation in the MTs P.P. school environment. Raudhatul Hasanah .. In addition, the need for the application of hybrid maize cultivation in the MTs P.P. school environment. Raudhatul Hasanah. Availability of organic waste treatment facilities as a means to process waste into compost. In addition, the USU PPM proposing team will provide multipurpose bins for the MTs P.P. school environment. Raudhatul Hasanah. The proposing team will practice compost processing and safeguarding hybrid corn in the school area. It is expected that later it will provide good direct benefits in the form of good food crops in the form of indirect benefits as knowledge and practice of MTs P.P. students. Raudhatul Hasanah. Partner involvement through community service programs by the community service team of MTs students. P.P. Raudhatul Hasanah is very high. This is indicated by the willingness of MTs school students. P.P. Raudhatul Hasanah was very enthusiastic and the active participation of students who attended the program was very satisfying. In addition this activity also helps MTs school students. P.P. Raudhatul Hasanah in studying and knowing waste management and its use through counseling and demonstrations. The success of the program in schools in MTs P.P. Raudhatul Hasanah Medan is largely determined by the participation of partners at each stage of the activities carried out. Partners namely schools in MTs P.P. Raudhatul Hasanah Medan really helped the implementation of community service programs in the USU community.
\end{abstract}

\section{Keywords: Waste management, compost, school, composter}

Abstrak
Keberadaan lembaga pendidikan sangat penting dan strategis untuk mendidik generasi yang berkualitas. Sasaran
dari program layanan ini adalah sekolah menengah pertama di Medan, yaitu MTs P.P. Raudhatul Hasanah di
Pesantren Ar-Raudlatul Hasanah di Medan. Pengelolaan dan pemanfaatan limbah dan melalui penyediaan
mikroorganisme tanah menjadi kompos dan perannya dalam penggunaan lahan melalui penanaman jagung hibrida di
MTs P.P. lingkungan sekolah. Raudhatul Hasanah .. Selain itu, perlunya aplikasi penanaman jagung hibrida di MTs
P.P. lingkungan sekolah. Raudhatul Hasanah. Ketersediaan fasilitas pengolahan limbah organik sebagai sarana
untuk mengolah sampah menjadi kompos. Selain itu, tim pengusul PPM USU akan menyediakan nampan multiguna
untuk MTs P.P. lingkungan sekolah. Raudhatul Hasanah. Tim pengusulan akan mempraktikkan pemrosesan kompos
dan menjaga jagung hibrida di area sekolah. Diharapkan nantinya akan memberikan manfaat langsung yang baik
dalam bentuk tanaman pangan yang baik dalam bentuk manfaat tidak langsung sebagai pengetahuan dan praktik
MTs P.P. siswa. Raudhatul Hasanah. Keterlibatan mitra melalui program layanan masyarakat oleh tim layanan
masyarakat siswa MTs. P.P. Raudhatul Hasanah sangat tinggi. Ini ditunjukkan oleh kemauan siswa sekolah MTs.
P.P. Raudhatul Hasanah sangat antusias dan partisipasi aktif siswa yang menghadiri program ini sangat memuaskan.
Selain itu kegiatan ini juga membantu siswa sekolah MTs. P.P. Raudhatul Hasanah dalam mempelajari dan
mengetahui pengelolaan limbah dan penggunaannya melalui konseling dan demonstrasi. Keberhasilan program di
sekolah-sekolah di MTs P.P. Raudhatul Hasanah Medan sangat ditentukan oleh partisipasi mitra pada setiap tahap


Diana Sofia Nasution et.al Utilization of organic waste

kegiatan yang dilakukan. Mitra yaitu sekolah di MTs P.P. Raudhatul Hasanah Medan sangat membantu implementasi program layanan masyarakat di komunitas USU.

\section{PENDAHULUAN}

Keberadaan lembaga pendidikan sangat penting dan strategis untuk mendidik generasi yang berkualitas. Sasaran program pengabdian ini adalah sekolah menengah tingkat pertama di Kota Medan, yakni di MTs P.P. Raudhatul Hasanah di Pesantren Ar-Raudlatul Hasanah Medan.

Mitra MTs P.P. Raudhatul Hasanah di Pesantren Ar-Raudlatul Hasanah Medan, sebagai sasaran program pengabdian pada masyarakat karena : (a) Kurikulum di MTs P.P. Raudlatul Hasanah adalah unik, dimana model dan kurikulumnya diambil sekolah normal dengan pendidikan pondok pesantren. Pelajaran, seperti yang diajarkan di beberapa pesantren pada umumnya dengan sistem sorogan, diajarkan di kelas-kelas. Pada saat yang sama, para santri/santriwati sudah wajib tinggal di dalam asrama dengan mempertahankan jiwa dan suasana kehidupan pesantren; (b) proses pendidikan berlangsung 24 jam. Pelajaran agama dan umum diberikan secara seimbang dalam jangka 6 tahun. Pendidikan keterampilan, kesenian, olahraga, organisasi dan lain-lain merupakan bagian dari kegiatan kehidupan santri/santriwati di pesantren.

Salah satu tantangan terbesar dalam menjaga kebersihan pondok adalah efektivitas dalam pengelolaan sampah pondok dari hulu ke hilir. Hal ini menjadi penting karena jumlah santri yang terus bertambah yang juga mengakibatkan meningkatnya volume sampah yang diproduksi.

Sampai saat ini sampah hanya dibuang ke tempat pembuangan sampah akhir, sehingga biaya pengangkutan dan operasional kebersihan tinggi. Perlunya informasi mengenai pengetahuan lingkungan sekolah bagi siswa Sekolah Menengah Pertama tentang pengelolaan dan pemanfaatan sampah. Sementara itu Upaya meningkatkan produksi jagung nasional dapat ditempuh dengan tiga pendekatan : peningkatan produktivitas, peningkatan intensitas tanam dan perluasan areal tanam ke lahan sub optimal (Asmarlaili et al., 2009; Sitinjak, 2017).

Tujuan dari tulisan ini adalah mengetahui pengaruh pemberian kompos terhadap pertumbuhan tanaman jagung hibrida.

\section{METODE PENDEKATAN}

Tim pengusul PPM USU akan melakukan kegiatan berdasarkan permasalahan di MTs P.P. Raudhatul Hasanah adalah sebagai berikut : (a) menangani masalah pengelolaan sampah dan pemanfaatannya menadi pupuk kompos; (b). pemanfaatan lahan sekitar sekolah melalui budidaya jagung hibrida; dan (c) meningkatkan kesadaran siswa sebagai generasi muda tentang pentingnya keberlanjutan pangan sejak usia dini serta peningkatan kesadaran pentingnya produktivitas lahan di lingkungan sekolah; dan (d) tersedianya tempat pengolahan sampah menjadi kompos dan tersedianya tempat penampungan sampah multiguna.

Pengelolaan dan pemanfaatan sampah dan melalui pemberian mikroorganisme tanah menjadi kompos dan perannya dalam pemanfaatan lahan melalui budidaya jagung hibrida di lingkungan sekolah MTs P.P. Raudhatul Hasanah. Pemanfaatan mikroorganisme tanah dalam pengelolaan sampah dan pembuatan kompos yang dapat meningkatkan kesuburan tanah menyebabkan bahan organic (Elpawati et al, 2015; Setyotini et al., 2006).. Selain itu perlunya penerapan budidaya tanaman jagung hibrida di lingkungan sekolah MTs P.P. Raudhatul Hasanah. Tersedianya tempat pengolahan sampah organic sebagai sarana untuk mengolah sampah menjadi kompos. Selain itu tim pengusul PPM USU akan menyediankan tempat sampah multiguna bagi lingkungan sekolah MTs P.P. Raudhatul Hasanah. 
Tim pengusul akan praktik pengolahan kompos dan penamanan jagung hibrida di areal lingkungan sekolah. Diharapkan nantinya memberikan manfaat baik langsung berupa tanaman pangan yang baik berupa manfaat tidak langsung sebagai pengetahuan dan praktik siswa MTs P.P. Raudhatul Hasanah.

Hasil pelaksanaan program pengabdian pada masyarakat telah dilaksanakan oleh tim pengabdian pada masyarakat Universitas Sumatera Utara berjalan dengan lancar dan sangat baik. Tim sudah selalau berkoordinasi dengan mitra agar kolaborasi dengan stakeholder dalam pelaksanaan program pengabdian pada masyarakat berjalan sesuai target yang ingin dihasilkan. Tercapainya target pelaksanakan kegiatam imi didukung oleh berbagai bantuan berbagai pihak terutama mitra yakni siswa sekolah di MTs P.P. Raudhatul Hasanah Medan. Mitra merupakan siswa di MTs P.P. Raudhatul Hasanah Medan.

\section{HASIL DAN PEMBAHASAN}

\subsection{Sosialisasi dan Penyuluhan Pengelolaan Sampah dan Pemanfaatannya}

Tahap pertama dalam program kegiatan pengabdian pada masyarakat oleh Tim USU kepada mitra dalam hal ini sekolah di MTs P.P. Raudhatul Hasanah Medan adalah penyuluhan kepada siswa. Siswa dan siswa sebagai target program ini, karena mereka memiliki potensi yang sangat besar dan menjaga dan memelihara lingkungan termasuk pengelolaan sampah dan pemanfaatannya. Disamping itu mitra mendapatkan manfaat lebih, karena siswa dan siswa mendapatkan sumber dan metode pengetahuan baru tentang perkembangan dan keterkaitan ilmu dan dapat lebih mengerti tentang pemanfaatan ilmu dan pengetahuan melalui praktek pengelolaan sampah, pembuatan pupuk organic dengan bantuan mikroorganisme tanah dan peerapannya pada tanaman jagug hibrida.

Pelaksanaaan program ini dilakukan di saung yang difasilitasi oleh mitra sehingga suasana kelas tidak terlalu kaku. Penyuluhan ini dibagi 2 (dua) sesi yakni pagi hari untuk siswa kelas $8 \mathrm{~N}$ dan sesi ke-dua (siang) dilakukan untuk siswi kelas 9G. Siswa dan siswi sekolah di MTs P.P. Raudhatul Hasanah Medan yang terlibat dalam program ini masing-masing 23 dan 25 orang. Pada kegiatan ini juga dibuat pra test dan post test sebelum dan sesudah penyuluhan untuk melihat tingkat pengetahuan siswa sebelum dan sesudah berjalannya program.

Keterlibatan siswa dalam penyuluhan tentang pengelolaan sampah dan pemanfaatannya melalui program pengabdian oleh tim pengabdian pada masyarakat terhadap siswa sekolah MTs. P.P. Raudhatul Hasanah ini cukup tinggi. Hal ini ditunjukkan kesediaan siswa sekolah MTs. P.P. Raudhatul Hasanah sangat antusias dan peran serta aktif siswa yang hadir saat pelaksanaan program sangat memuaskan. Selain itu kegiatan ini juga membantu siswa sekolah MTs. P.P. Raudhatul Hasanah dalam mempelajari dan mengenal pengelolaan sampah dan pemanfaatannya melalui penyuluhan dan demonstrasi. 

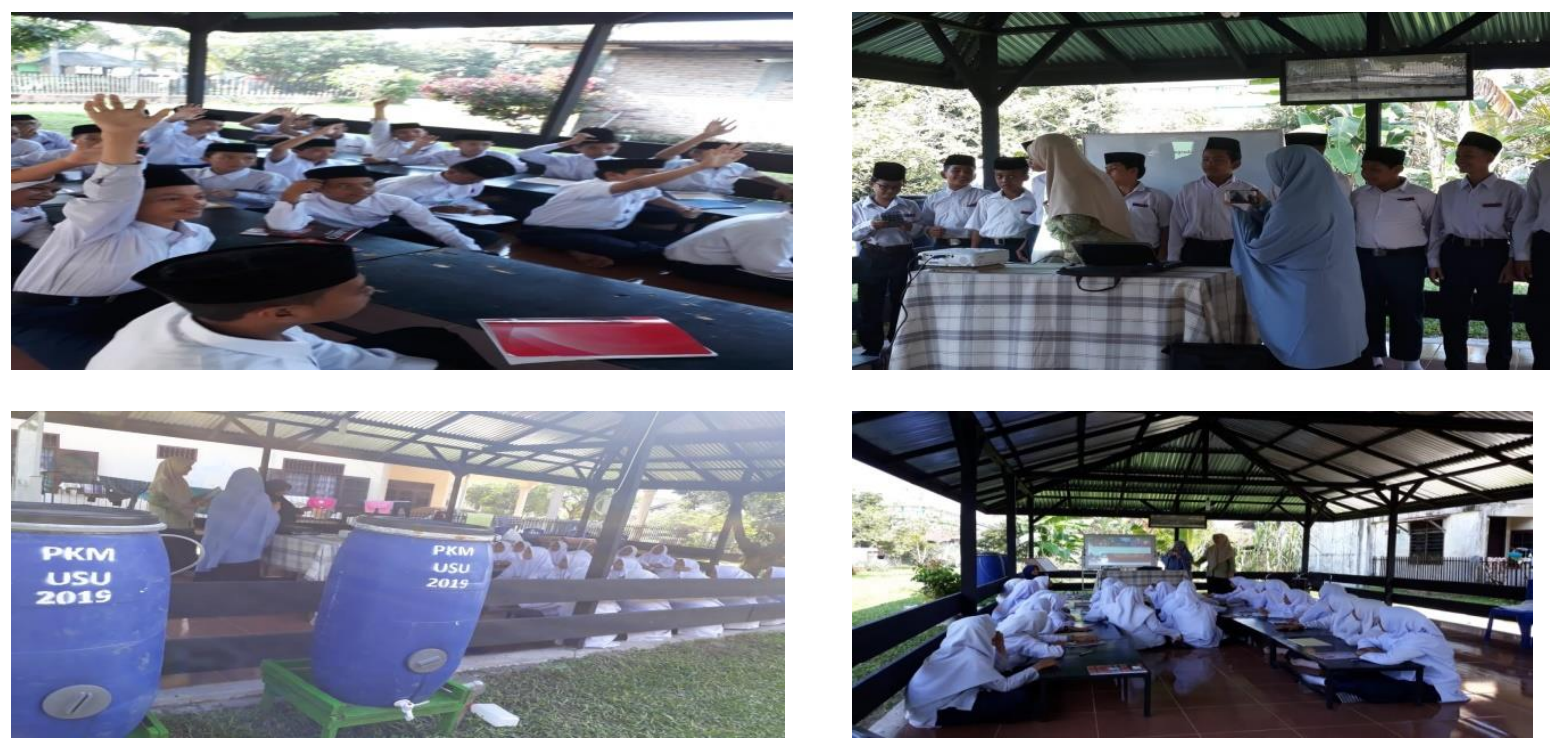

Gambar 3.1. Kegiatan sosialisasi dan penyuluhan

Keberhasilan program di sekolah di MTs P.P. Raudhatul Hasanah Medan banyak ditentukan oleh partisipasi mitra pada setiap tahapan kegiatan yang dilakukan. Mitra yakni sekolah di MTs P.P. Raudhatul Hasanah Medan sangat membantu terselenggaranya kegiatan program pengabdian pada masyarakat USU.

\subsection{Pelatihan Praktek Budidaya Jagung Hibrida}

Pelaksanaan program ini berhasil dibuat 3 plot untuk demplot pelaksanaan praktek dan pengamatan budidaya jagung hibrida. Plot yang dibuat sesuai dengan perlakuan yang ingin diketahui tahap pertumbuhan pada setiap perlakuan yang ingin diuji, yakni pemberian kompos organik dan pupuk cair organik. Kompos organik dan pupuk cair organik ini adalah hasil pengolahan sampah organik dengan bantuan mikroorganisme EM4 pada dekomposer.

Keberhasilan kegiatan di MTs P.P. Raudhatul Hasanah Medan juga didukung dari sumberdaya manusia tim pengabdian USU dan bantuan Fakultas Pertanian dan Lembaga Pengabdian pada Masyarakat USU yang banyak membantu kegiatan ini. Pendekatan yang dilakukan adalah memberikan motovasi kepada siswa melalui bantuan bibit dan penanaman bibit jagung hibrida di lahan sekolah siswa menjadikan kegiatan ini berjalan dengan baik.

Pelaksanaan kegiatan ini juga melibatkan mahasiswa sebagai usaha memberikan pengalaman mereka menghadapi tantangan pembangunan pertanian yang semakin komplek peningkatan kemampuan sumberdaya manusia (SDM). Peningkatan sumberdaya manusia termasuk di pedesaan merupakan salah satu faktor yang perlu mendapat perhatian pemerintah. Dengan adanya peningkatan kemampuan di MTs P.P. Raudhatul Hasanah Medan, pemanfaatan lahan di lahan sekolah agar berfungsi lebih optimal. 

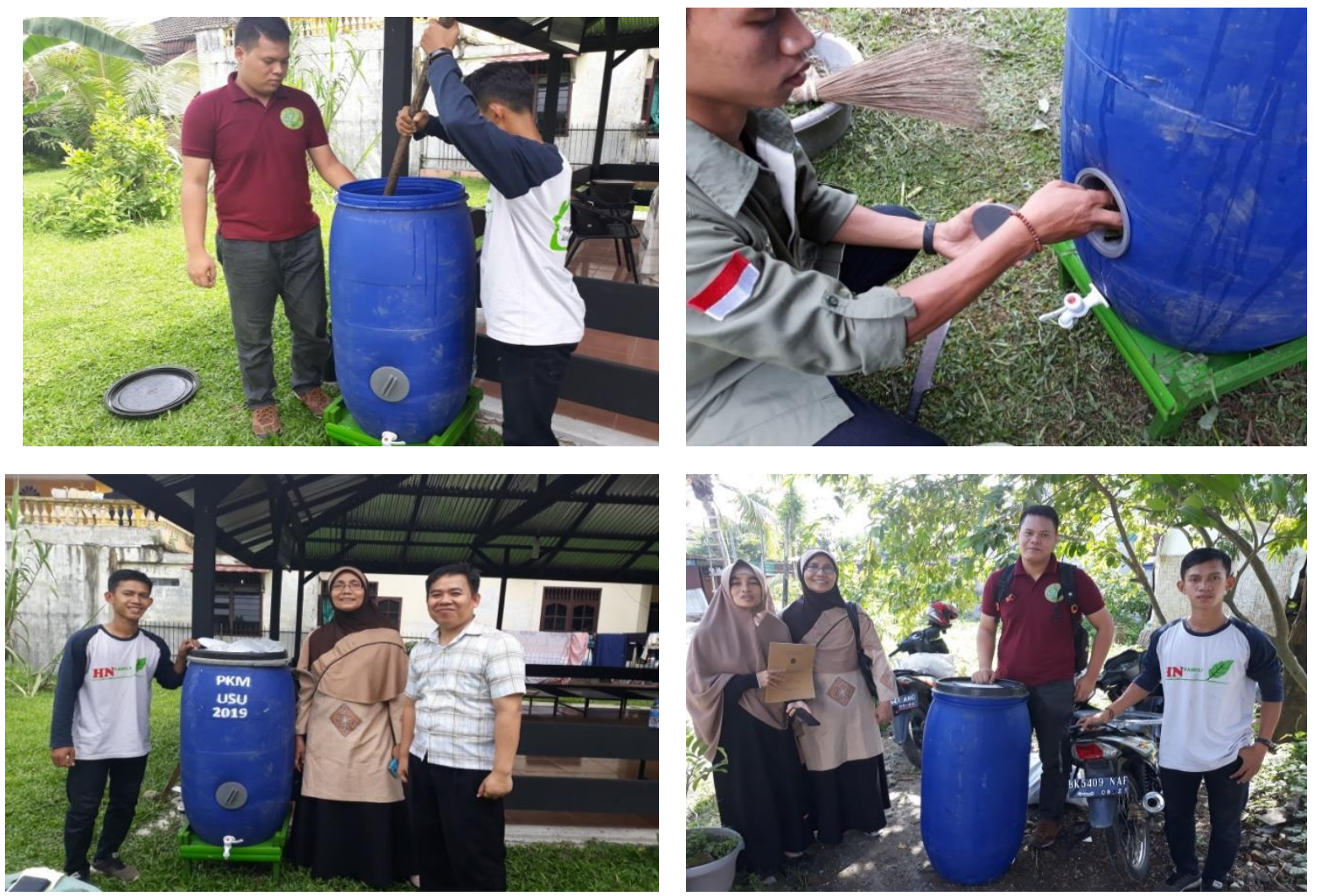

Gambar 3.2. Pemeliharaan komposter

Tim pengabdian pada masyarakat juga telah memberikan pendidikan kepada masyarakat akan pentingnya mewujudkan pengetahuan siswa. Hal ini dapat dilihat dari peran dan partisipasi masyarakat mendapatkan aprisiasi yang tinggi dari masyarakat di MTs P.P. Raudhatul Hasanah Medan. Masyarakat sebagai mitra dari tim pengabdian pada masyarakat semakin menyadari pentingnya keberagaman pangan termasuk penanaman jagung hibrida untuk meningkatkan produktivitas lahan sekolah siswa. Hal ini menyadarkan masyarkat pentingnya masalah pangan bukan hanya menjadi tanggungjawab unsur pemerintah, juga peran perguruan tinggi termasuk yang telah dilakukan tim pengabdian pada masyarakat Universitas Sumatera Utara selama ini.

Untuk lebih menumbuhkan motivasi dan mengoptimalkan lahan pertanian mereka dengan begitu tingginya animo dan partisipasi siswa di MTs P.P. Raudhatul Hasanah Medan. Tim pengabdian pada masyarakat USU juga memberikan bantuan bibit jagung hibrida kepada siswa dan melaksanan penanaman jagung hibrida di lokasi pengabdian. Pelaksanaan pengabdian pada masyarakat oleh tim USU mampu meningkatkan produktivitas lahan sekolah dalam upaya mewujudkan pengetahuan siswa di di MTs P.P. Raudhatul Hasanah Medan. 

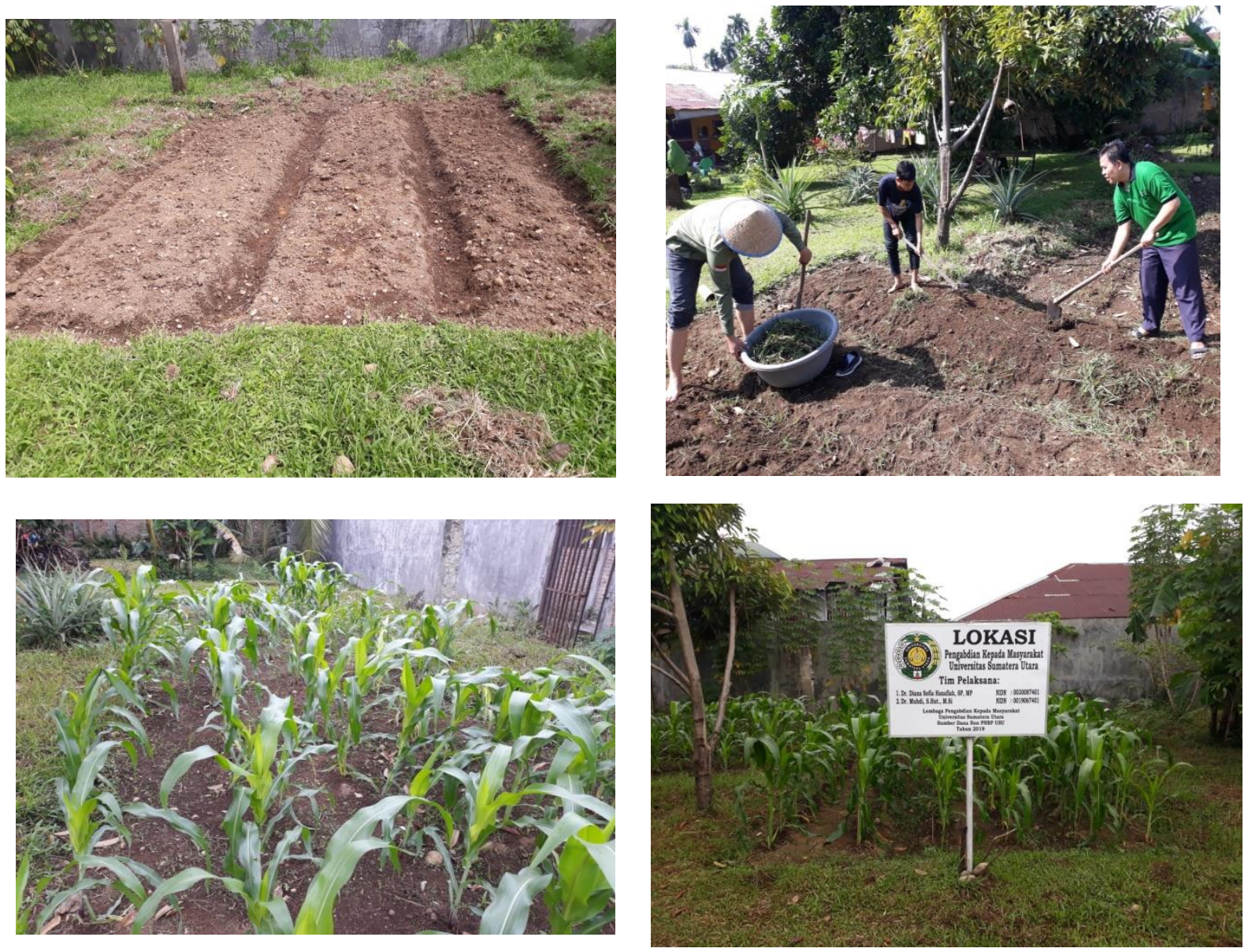

Gambar 3.3. Program pembuatan demplot.

Oleh karena itu, salah satu cara untuk usaha yang dilakukan adalah dengan memotivasi siswa di MTs P.P. Raudhatul Hasanah Medan agar lebih efektif berpartisipasi dalam pelaksanaan program pengabdian pada masyarakat ini untuk peningkatan produksi dan produktivitas lahan sekolah mereka dalam mewujudkan pengetahuan siswa. Pelaksanaan kegiatan ini satu sarana untuk meningkatkan motivasi dan partisipasi siswa secara aktif agar siswa mau dan mampu meningkatkan produksi dalam rangka mewujudkan pengetahuan siswa di MTs P.P. Raudhatul Hasanah Medan.

\subsection{Pemberian Pupuk Kompos dan Pertumbuhan Jagung Hibrida}

Untuk mendapatkan data hasil pengabdian pada masyarakat ini juga dilakukan penguuran parameter pertumbuhan jagung hibrida. Hasil pengamatan pengaruh perlakuan pemberian pupuk kompos terhadap parameter tinggi tanaman dapat dilihat pada Tabel 1 dan Gambar 1. 
Diana Sofia Nasution et.al Utilization of organic waste

Tabel 1. Rataan tinggi tanaman dengan perlakuan pupuk organik cair

\begin{tabular}{lcccc}
\hline \multirow{2}{*}{ Perlakuan } & \multicolumn{4}{c}{ Tinggi tanaman (MST) } \\
\cline { 2 - 5 } & 2MST & 3MST & 4MST & 5MST \\
\hline A1 & 25,40 & 58,10 & 83,70 & 120,60 \\
A2 & 24,70 & 56,10 & 85,50 & 128,20 \\
A3 & 25,50 & 56,60 & 88,40 & 123,20
\end{tabular}

Tabel 1 menunjukkan pemupukan dengan kompos memiliki pertumbhuhan tinggi tanaman yang lebih baik dibandingkan dengan tanaman control (A3). Hasil pengamatan ini menunjukkan bahwa pada awal pertumbuhan tanaman $2 \mathrm{MS}$, tanaman jagung control memiliki pertumbuhan yang lebih tinggi. Berdasarkan hasil uji statistic perlakuan pemupukan berpengaruh tidak nyata terhadap parameter tinggi tanaman.

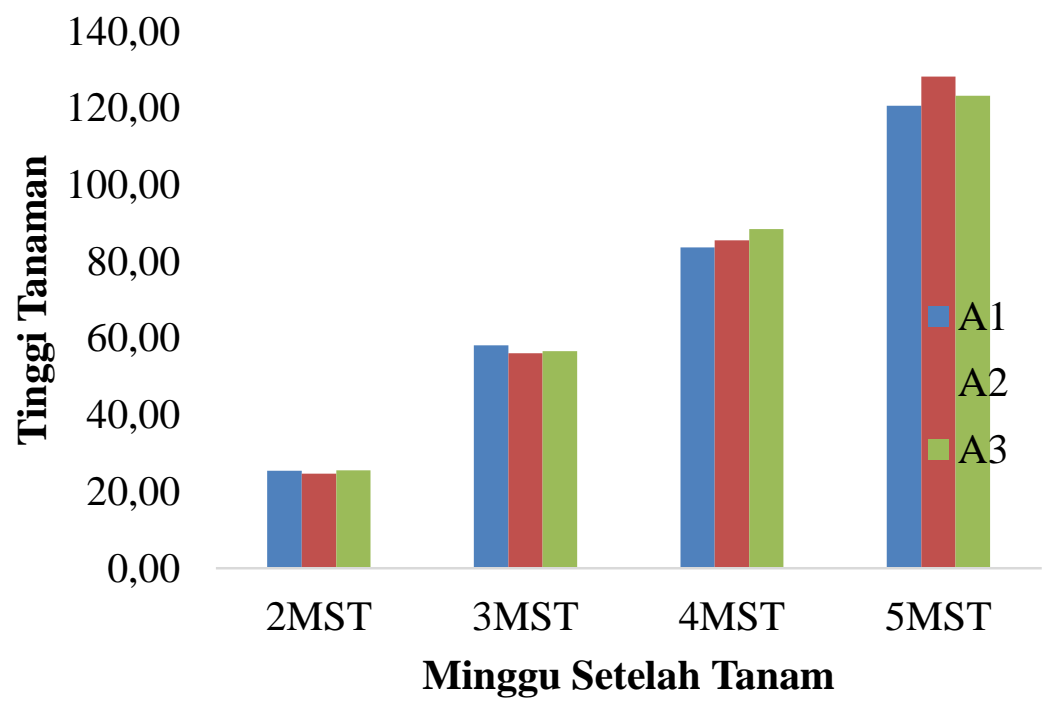

Gambar 3.4. Histogram rataan tinggi tanaman dengan perlakuan pupuk organik cair

Pengamatan parameter pertumbuhan yang dikukr berikutnya adalah diameter batang tanaman jagung. Hasil pengamatan menunjukkan bahwa pada petak tanaman A1 memiliki diameter tanaman yang lebih besar dibandingkan dengan perlakuan lain. Hasil pengukuran dapat dilihat pada Tabel 2. 
Tabel 2. Rataan diameter batang tanaman dengan perlakuan pupuk organik cair

\begin{tabular}{llll}
\hline \multirow{2}{*}{ Perlakuan } & \multicolumn{3}{l}{ Diameter tanaman (MST) } \\
\cline { 2 - 4 } & 3MST & 4MST & 5MST \\
\hline A1 & 4,05 & 5,25 & 7,7 \\
A2 & 3,7 & 5,4 & 7,3 \\
A3 & 3,85 & 4,8 & 6,2 \\
\hline
\end{tabular}

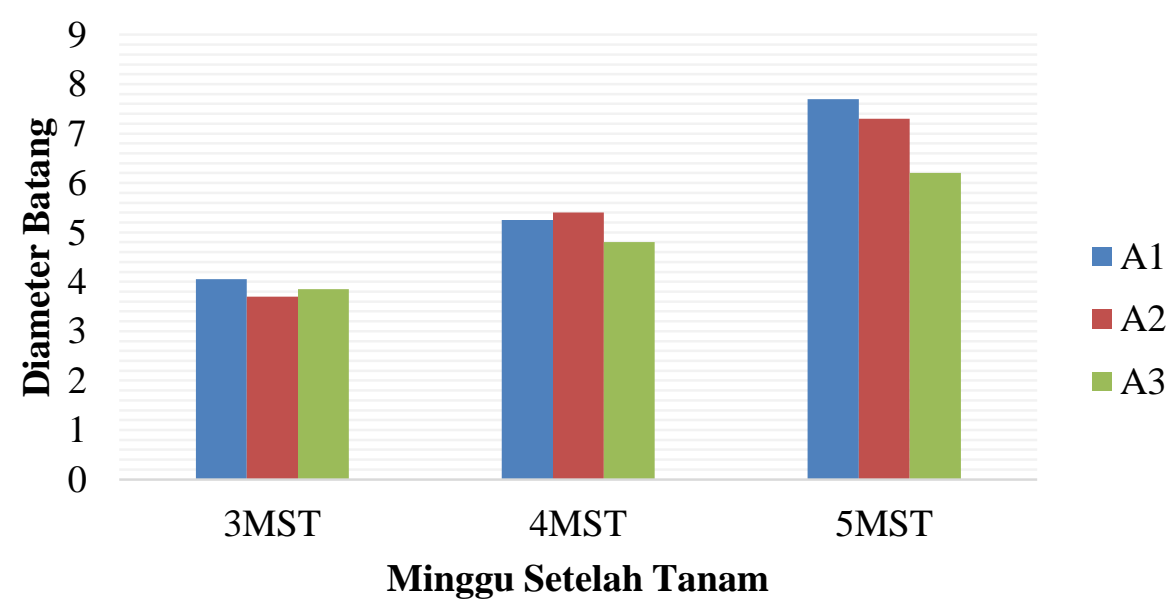

Gambar 3.4. Histogram rataan diameter batang tanaman dengan perlakuan pupuk organik cair

\section{KESIMPULAN}

Keterlibatan mitra melalui program pengabdian oleh tim pengabdian pada masyarakat terhadap siswa/siswi sekolah MTs. P.P. Raudhatul Hasanah ini sangat tinggi. Hal ini ditunjukkan kesediaan siswa sekolah MTs. P.P. Raudhatul Hasanah sangat antusias dan peran serta aktif siswa yang hadir saat pelaksanaan program sangat memuaskan. Selain itu kegiatan ini juga membantu siswa sekolah MTs. P.P. Raudhatul Hasanah dalam mempelajari dan mengenal pengelolaan sampah dan pemanfaatannya melalui penyuluhan dan demonstrasi.

Keberhasilan program di sekolah di MTs P.P. Raudhatul Hasanah Medan banyak ditentukan oleh partisipasi mitra pada setiap tahapan kegiatan yang dilakukan. Mitra yakni sekolah di MTs P.P. Raudhatul Hasanah Medan sangat membantu terselenggaranya kegiatan program pengabdian pada masyarakat USU.

\section{UCAPAN TERIMAKASIH}

Tim pengabdian pada masyarakat mengucapkan terima kasih kepada pihak LPPM USU yang telah memberikan dana kepada pengabdian ini. Terima kasih juga kepada pihak mitra yang telah koopratif di dalam pelaksanaan pengabdian ini. 


\section{DAFTAR PUSTAKA}

Asmarlaili, S.H., T. Sabrina, H. Guchi, 2009. Biologi dan Ekologi Tanah. USU Press. Medan. Hal 329-334.

Elpawati, Stephani, D.D.Y.K.S., Dasumiati. 2015. Optimasi penggunaan pupuk kompos dengan penambahan effective microorganism 10 (EM10) pada produktivitas tanaman jagung (Zea mays L.). Al-Kauniyah Jurnal Biologi Volume 8 Nomor 2:77-87.

Setyotini, D. R., Saraswati, E.K. Anwar. 2006. Kompos. Jurnal Pupuk Organik dan Pupuk Hayati. 2(3), 11-40.

Sitinjak, M. A., 2017. Isolasi dan Uji Potensi Bakteri Pereduksi Sulfat dari Berbagai Sumber Terhadap Perubahan Media Tumbuh di Lobarotarium. SKRIPSI. USU. Medan. 